\title{
17-Beta-Estradiol Increases Mitogenic Activity of Medium from Cultured Preadipocytes of Massively Obese Persons
}

\author{
Stephen C. Cooper and Daniel A. K. Roncari \\ Julia McFarlane Diabetes Research Unit, Departments of Medicine and Medical Biochemistry, The University of Calgary; and \\ Foothills Hospital, Calgary, Alberta, Canada
}

\begin{abstract}
Having reported that omental preadipocytes from massively obese persons release into the culture medium proteins mitogenic for preadipocytes, this study aimed to determine whether estrogens contribute to the production of these factors. Subcultured omental preadipocytes from 13 massively obese women were grown in the presence or absence of 17 -beta-estradiol, and during the last $24 \mathrm{~h}$ the conditioned medium was prepared in the absence of serum. Media from cells of 8 of 13 subjects contained significantly higher mitogenic activity when grown in the presence of 17-beta-estradiol. 17-Alpha-estradiol was not effective. The bioassay system involved rat perirenal preadipocytes, since these have been well characterized. Partial purification by gel filtration chromatography indicated that the estrogen-dependent factors had $M_{\mathrm{r}}>250,000$ and $\sim 30,000$. Thus, estrogens might contribute to the development of massive obesity in genetically susceptible subjects by promoting the production of paracrine/autocrine principles by adipose cells.
\end{abstract}

\section{Introduction}

The finding that 17-beta-estradiol $\left(\beta \mathrm{E}_{2}\right)^{1}$ stimulated the replication of human omental preadipocytes in culture evoked questions regarding the possible significance of this observation in vivo and the mechanism mediating this effect (1). We postulated that enhanced preadipocyte multiplication might be involved in the alterations in the configuration of adipose tissue in girls at puberty.

We subsequently also found that human preadipocytes released into the culture medium proteins mitogenic on other preadipocytes (2). It was suggested that these principles represented autocrine/paracrine factors. Notably, moreover, preadipocytes from massively obese persons released substantially higher mitogenic activity than cells from lean persons (2).

Part of this work was presented in 1986 at the Meeting of the Canadian Society for Clinical Investigation, Toronto, Canada, and appeared in abstract form in 1986 (Clin. Invest. Med. 9:A36).

Address reprint requests to Dr. D. A. K. Roncari, Department of Medicine, Sunnybrook Medical Centre, University of Toronto, 2075 Bayview Avenue, Toronto, Ontario, Canada M4N 3M5.

Received for publication 18 July 1988 and in revised form 8 February 1989

1. Abbreviations used in this paper: $\beta \mathrm{E}_{2}, 17$-beta-estradiol.

J. Clin. Invest.

(c) The American Society for Clinical Investigation, Inc.

0021-9738/89/06/1295/05 \$2.00

Volume 83, June 1989, 1925-1929
In view of the preceding findings, and knowing that estrogens bring about the release of mitogenic autocrine/paracrine polypeptides from the MCF-7 mammary carcinoma cell line $(3,4)$, we have postulated that estrogens might exert their mitogenic effect on preadipocytes through local factors. Using cells from massively obese women, we now present evidence in favor of this mechanism.

\section{Methods}

Subjects. After informed consent, omental adipose tissue was obtained from 13 massively obese women, 25-45 yr of age, undergoing gastric restriction surgery. Massive obesity was defined arbitrarily by a body weight $>170 \%$ of the references provided by the revised Metropolitan Life Insurance Company Tables (5). Subjects were considered lean when their body weight was up to $119 \%$ of reference, and moderately obese up to $170 \%$ of reference.

Isolation and culture of preadipocytes. Except for the specified modifications, human omental preadipocytes and rat perirenal preadipocytes (from male Sprague-Dawley rats weighing 150-175 g) were isolated and cultured according to our reported methods (1, 2, 6-11).

To isolate human preadipocytes, vascular elements were excised from fat tissue, which was then digested with $1 \mathrm{mg} / \mathrm{ml}$ collagenase in $75-\mathrm{cm}^{2}$ flasks containing HBSS at $37^{\circ} \mathrm{C}$ for $35 \mathrm{~min}$. After mild centrifugation the pellet was suspended in Alpha MEM supplemented with $15 \%$ (vol/vol) fetal bovine serum, sodium bicarbonate, and $15 \mathrm{mM}$ Hepes, pH 7.4, as well as antibiotics. Inoculation, cell washing, and change of medium were conducted as reported $(2,10)$. When primary cultures were contaminated with endothelial cells, these were removed with trypsin and direct scraping from plates. After reaching monolayer confluence, they were washed with HBSS (devoid of calcium and magnesium) and then incubated with $0.25 \mathrm{mg} / \mathrm{ml}$ trypsin and $2 \mathrm{mM}$ $\mathrm{Na}_{2} \mathrm{EDTA}$ in the Ca- and Mg-free HBSS at $37^{\circ} \mathrm{C}$ for $10 \mathrm{~min}$. After mild centrifugation of the detached cells, $\sim 250,000$ cells $/ 75-\mathrm{cm}^{2}$ flask and $\sim 400,000 / 150-\mathrm{cm}^{2}$ flask, were grown in 15 and $30 \mathrm{ml}$, respectively, of the described supplemented Alpha MEM. Up to six passages were carried out by the same method.

To isolate rat preadipocytes, perirenal fat tissue was digested with 1 $\mathrm{mg} / \mathrm{ml}$ collagenase at $21-24^{\circ} \mathrm{C}$ for $15 \mathrm{~min}$. Other details of culture were as described for human preadipocytes and as reported $(10,11)$. There was never any appreciable contamination with endothelial cells.

Preparation of conditioned medium. The human preadipocytes in passages 2-6 were grown in the presence of either $10^{-9} \mathrm{M} \beta \mathrm{E}_{2}$ or vehicle ( $10 \mathrm{ml}$ methanol diluted $10^{4}$-fold with Alpha MEM and $10^{2}$ fold with supplemented Alpha MEM). In some experiments, $10^{-9} \mathrm{M}$ 17-alpha-estradiol $\left(\alpha \mathrm{E}_{2}\right)$ was substituted for the beta epimer. 1-2 d after confluence the cells were washed four times with HBSS and then incubated for $24 \mathrm{~h}$ with Alpha MEM devoid of nucleosides, and without serum or estrogen. The overlying medium was centrifuged at $40,000 \mathrm{~g}$ for $40 \mathrm{~min}$ and decanted. The resulting supernatant fluid was designated "conditioned medium." It was concentrated 75-100 times to $\sim 1 \mathrm{mg} / \mathrm{ml}$ protein under $\mathrm{N}_{2}$ at $55 \mathrm{lb} /$ in. $^{2}$ with a concentrator and a filter excluding proteins of $M_{\mathrm{r}} 1,000$ (Amicon Corp., Danvers, MA). The conditioned medium was stable in terms of mitogenic activity at $-80^{\circ} \mathrm{C}$ in liquid $\mathrm{N}_{2}$ for at least $6 \mathrm{mo}$. Protein concentration was determined with the assay kit calibrated with gamma globulin (Bio-Rad Laboratories, Richmond, CA). 
Bioassay. Rat perirenal preadipocytes were chosen for the assay because under appropriate culture conditions almost all of these cells can undergo adipose differentiation $(10,11)$. Except for the details to be described, replication of rat perirenal preadipocytes was assessed as previously reported (10). The preadipocytes in second passage were seeded in 24-well plates (Linbro, Flow Laboratories, Hamden, CT) at a density of $\sim 10,000$ cells/well in $0.5 \mathrm{ml}$ supplemented Alpha MEM. After $\sim 24 \mathrm{~h}$ the preadipocytes were washed thoroughly and rendered quiescent by decreasing the concentration of fetal bovine serum to $0.5 \%$, at the same time switching to Alpha MEM without nucleosides. After culture for an additional $24 \mathrm{~h}$, conditioned media (from human omental preadipocytes grown in the presence or absence of estrogen) or ordinary media were added at equal volumes of $25 \mu 1$. The positive control consisted of $5 \%$ serum. After a further $24 \mathrm{~h}, 1 \mu \mathrm{Ci}(37 \mathrm{kBq})$ of $\left[{ }^{3} \mathrm{H}\right]$ thymidine (sp act $43 \mathrm{Ci} / \mathrm{mmol}$; Amersham International, Amersham, UK) was added to each well to a total volume of $0.5 \mathrm{ml}$. After 24 additional $h$ the cells were washed with HBSS devoid of calcium and magnesium, and detached with trypsin-EDTA. The suspended cells were placed on filters (Whatman Laboratory Products Inc., Clifton, NJ) in a Millipore apparatus (Millipore/Continental Water System, Bedford, MA) (10). The filters were washed twice with $5 \mathrm{ml} 5 \%$ TCA, dried, and suspended in Econofluor scintillation fluid to count the radioactivity in a beta counter (RackBeta; LKB, Wallac Oy, Finland). $\left[{ }^{3} \mathrm{H}\right]$ Thymidine incorporation into DNA correlated well with cell enumeration with a Coulter Counter (Coulter Electronics Inc., Hialeah, FL), which was in turn validated with a hemocytometer.

Superose $6 B$ gel filtration. Concentrated conditioned media were partially purified on a $1.6 \times 50-\mathrm{cm}$ Superose 6B column (K16/70; Pharmacia Fine Chemicals, Piscataway, NJ), equilibrated, and eluted with $0.05 \mathrm{M}$ ammonium acetate, $\mathrm{pH} 7.0$, containing $0.05 \mathrm{M}$ 2-mercaptoethanol, at $4^{\circ} \mathrm{C}$ and flow rate of $0.5 \mathrm{ml} / \mathrm{min}$. 2-ml fractions were collected and pooled, as will be indicated. The pools were then concentrated with an Amicon apparatus, and a filter of molecular exclusion at 1,000 D. Protein concentrations and mitogenic activity were determined as described.

\section{Results}

Analysis of data. For each factor and factor level the $\left[{ }^{3} \mathrm{H}\right]$ thymidine radioactivity incorporated into rat perirenal preadipocyte DNA was determined for 3-5 wells and averaged. For each set the SEM was calculated. Because of the differences between plates caused by uneven cell distribution and variation in growth, the results were expressed as follows: mean disintegrations per minute of test sample/mean disintegrations per minute with medium not exposed to cells to give' percent of control. This value was used to compare the mitogenic activity of conditioned media prepared from cells grown with or without estrogen. The paired sample, one-tailed $t$ test was used to determine statistical significance. As far as the reproducibility of the bioassay is concerned, variance for conditioned medium from the same cell strain at a given passage was significantly less $(P<0.05)$ than variance for comparisons between cell strains under analogous conditions $(P<0.0005)$.

Mitogenic activity of conditioned media. Fig. 1 indicates the effect of $\beta \mathrm{E}_{2}$ added to the growth medium on the mitogenic activity of the respective conditioned media. In 8 of 13 cases $\beta \mathrm{E}_{2}$ led to medium capable of stimulating rat preadipocyte replication to a significantly higher degree than did medium from control cells. Except for cells from subject 9, moreover, a trend toward greater multiplication was observed in the four other cases (Fig. 1). The conditioned media in each case were prepared from the same number of human preadipocytes, $\sim 1$ million $/ 5 \mathrm{ml}$ medium. For these comparisons, $100 \mu \mathrm{g} / \mathrm{ml}$ of protein was used for the assays, except for subjects 6-9, for

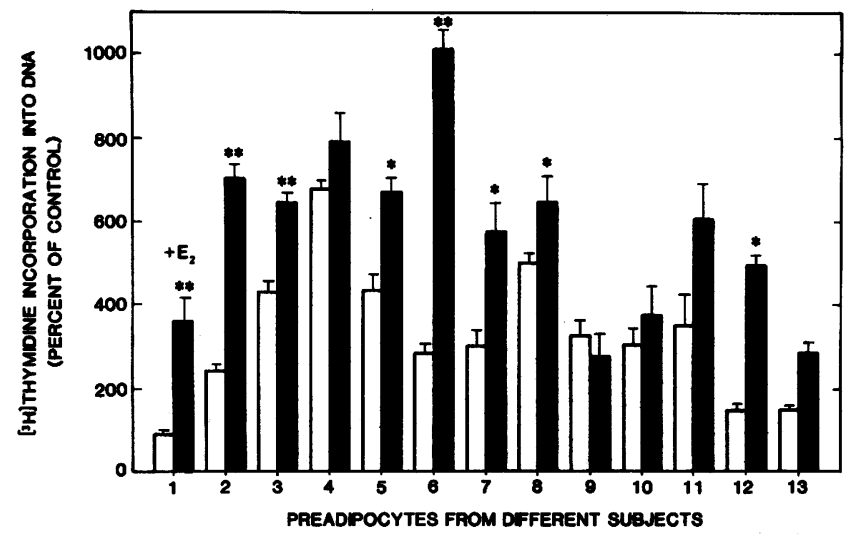

Figure 1. Effect of $\beta \mathrm{E}_{2}$ on release of mitogenic factors by human omental preadipocytes. The mitogenicity of estradiol-affected (cells grown in the presence of $10^{-9} \mathrm{M} \beta \mathrm{E}_{2}$ ) and ordinary conditioned media from the preadipocytes were compared. As detailed in the text, the incorporation of $\left[{ }^{3} \mathrm{H}\right]$ thymidine into DNA of rat perirenal preadipocytes was taken as a measure of the degree of replication of these cells (mitogenicity). This measurement was divided by the quantity of $\left[{ }^{3} \mathrm{H}\right]$ thymidine incorporated by cells grown with medium devoid of factors from cells, resulting in the percent of control shown. For each cell strain, the results for $100 \mu \mathrm{g} / \mathrm{ml}$ of protein in the conditioned media are shown except from subjects 6-9, for which the highest levels of protein tested were 50,90,60, and 80 $\mu \mathrm{g} / \mathrm{ml}$, respectively. Error bars represent SEM derived from the average of three to five determinations for each experimental condition. Open bars represent the mitogenicity of ordinary conditioned media, solid bars that of estradiol-affected conditioned media. Statistical analysis was carried out by the one-tailed $t$ test for paired samples. ${ }^{*} P$ $<0.05 * * P<0.005)$.

which the highest levels of protein tested were $50,90,60$, and $80 \mu \mathrm{g} / \mathrm{ml}$, respectively (Fig. 1). However, in the case of cells from subject 10 , a significant difference was only observed at lower protein levels (i.e., $10-20 \mu \mathrm{g} / \mathrm{ml}$ ). The subjects whose cells responded to $\beta \mathrm{E}_{2}$, as indicated by the mitogenic activity of the conditioned medium, did not reveal any obvious clinical differences, including degree of adiposity, from the persons whose cells were not influenced significantly. It should be emphasized that, in contrast to the conditioned media, $\beta \mathrm{E}_{2}$ did not directly stimulate the replication of rat perirenal preadipocytes.

Effects of different protein concentrations. The possible effects of different protein concentrations in the various conditioned media were examined in the case of preparations from 10 subjects. Four examples are presented in Fig. 2, one (subject 4 ) in which no difference for $\beta \mathrm{E}_{2}$ was found (Fig. $2 A$ ), and three in which statistically significant differences were observed. In the case of conditioned media prepared from preadipocytes from the other three subjects $(5,7$, and 10$)$, a significant effect of $\beta E_{2}$ was already observed at $10-20 \mu \mathrm{g} / \mathrm{ml}$ protein, but the significance was no longer evident at $50 \mu \mathrm{g} / \mathrm{ml}$ for subject 10 (Fig. 2, $B-D$ ). As shown in Figs. 1 and $2 A$, the conditioned medium prepared with cells from subject 4 , grown without added estrogen, had relatively higher mitogenic activity than conditioned media from preadipocytes grown under the same conditions derived from the other subjects. It is conceivable that the cells from subject 4 , possibly on a genetic basis, produced larger quantities of mitogenic compounds. These would then stimulate the rat preadipocytes maximally, 

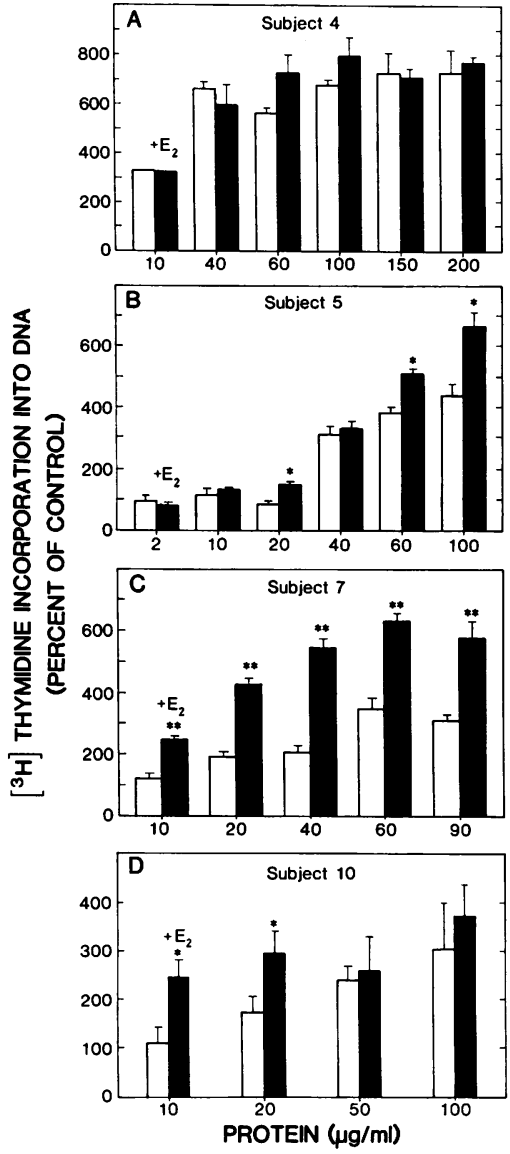

Figure 2. Influence of protein concentration on the mitogenic activity of conditioned media. Ordinary (open bars) and estradiol-affected media (solid bars) were compared in the case of preadipocyte strains from subjects 4 $(A), 5(B), 7(C)$, and 10 $(D)$. Error bars represent the SEM derived from the average of three to five determinations for each experimental condition. The percent of control was calculated, and other details are as described for Fig. 1. ${ }^{*} P<0.05$ ** $P<0.005$ ).

accounting for lack of an additional significant increment in the mitogenic activity of the conditioned medium prepared with cells cultured with added estrogen.

Comparison of $\alpha E_{2}$ with $\beta E_{2}$. In five experiments, each with a preadipocyte strain from a different subject, cells were grown in parallel experiments with either $\beta \mathrm{E}_{2}$ or $\alpha \mathrm{E}_{2}$. As exemplified by Fig. 3, $\alpha \mathrm{E}_{2}$ did not lead to conditioned medium with mitogenic activity significantly greater than medium derived from preadipocytes grown in the absence of this epimer of $\beta \mathrm{E}_{2}$. The latter did lead to significantly higher activity at $20-50 \mu \mathrm{g} / \mathrm{ml}$, but not at $2 \mu \mathrm{g} / \mathrm{ml}$ protein in the conditioned medium.

Three experiments were aimed at estimating the range of maximal activity of the mitogenic factors in the conditioned medium prepared from omental preadipocytes grown with and without $\beta \mathrm{E}_{2}$. As exemplified by Fig. 4, 6-h pulses of $\left[{ }^{3} \mathrm{H}\right]$ thymidine yielded data suggesting that the factors acted maximally at 24-30 h, at least for conditioned media from cells grown with added $\beta \mathrm{E}_{2}$. In the absence of supplementation with this hormone no inference could be made, but taking the data of all three experiments together a trend toward a similar temporal pattern was observed. The timing of the bioassay does not influence the results; in particular, the rat preadipocytes do not require conditioned medium, and thus the active compounds do not prolong their survival.

Superose $6 B$ molecular sieve chromatography. Conditioned media from preadipocytes of subjects 3,5 , and 8 , grown with or without $\beta E_{2}$, were partially purified in each case by molecular sieve chromatography on a Superose $6 \mathrm{~B}$ column, as

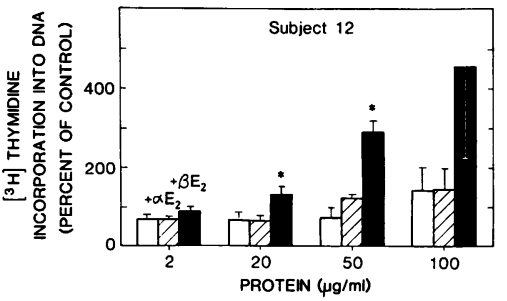

Figure 3. Influence of 17-alpha-estradiol compared with $\beta \mathrm{E}_{2}$. The mitogenic activity was determined for ordinary conditioned media (open bars), $\beta \mathrm{E}_{2}$-affected conditioned media (solid bars), and

conditioned media from cells grown with 17-alpha-estradiol (hatched bars) from preadipocytes of subject 12 . The mitogenic activity, shown as percent of control, was calculated as indicated in Fig. 1. Error bars represent the SEM derived from the average of three to five determinations for each experimental condition (each bar). Other details are described in the legend to Fig. $1 .{ }^{*} P<0.05$.

exemplified for preparations from subject 5 (Fig. 5). While the protein profiles were very similar, scanning from the exclusion volume to the total column volume, pools $1\left(M_{\mathrm{r}}>250,000\right)$ and $4\left(M_{\mathrm{r}} \sim 30,000\right)$ revealed significantly higher mitogenic activity when the conditioned medium was derived from cells grown with added $\beta \mathrm{E}_{2}$, as compared with those not supplemented with hormone. In each case, lower protein levels (4-10 $\mu \mathrm{g} / \mathrm{ml})$ resulted in mitogenic activity, reflecting some degree of purification (3-5-fold) relative to the original conditioned medium. At the present stage of characterization, we do not know whether the $M_{\mathrm{r}} \sim 30,000$ factor(s) is related to the $M_{\mathrm{r}}$ $>250,000$ compound(s), either as a monomer or part of an in vitro aggregate, nor do we know of a relationship to any known entity.

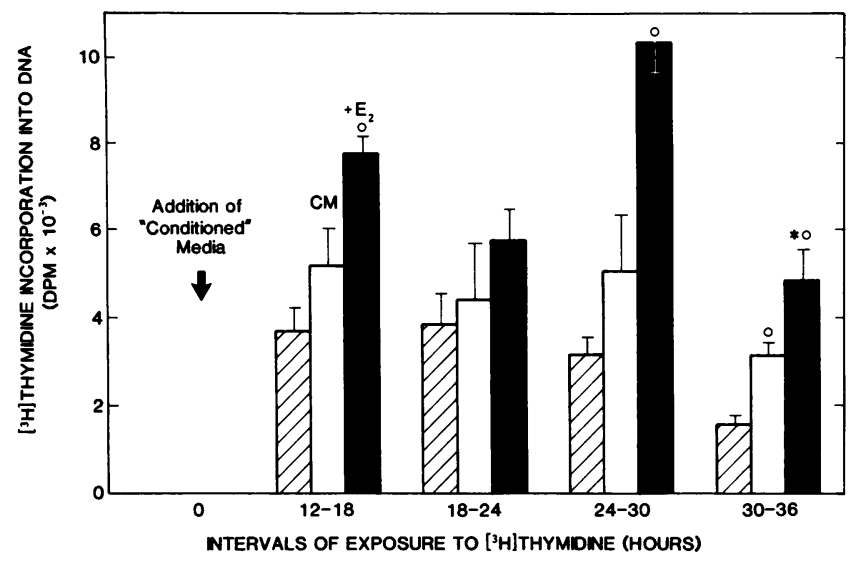

Figure 4. Addition of $\left[{ }^{3} \mathrm{H}\right]$ thymidine pulses at different times after introduction of conditioned media prepared with preadipocytes from subject 10 . At the time designated 0 , equal aliquots of estradiol-affected or ordinary conditioned media were added to the culture wells. $\left[{ }^{3} \mathrm{H}\right]$ Thymidine was added $12,18,24$, or $30 \mathrm{~h}$ later, and the cells were harvested $6 \mathrm{~h}$ after each addition. The degree of cell division is indicated by the amount of $\left[{ }^{3} \mathrm{H}\right]$ thymidine incorporated into DNA, measured in disintegrations per minute. The mitogenic activity, when no factors were added, is shown by hatched bars, that of ordinary conditioned medium by open bars, and that of estradiol-affected conditioned medium by solid bars. Error bars represent the SEM, derived from the average of three determinations for each experimental condition. *Significant difference $(P<0.05)$ between estradiol-affected and corresponding ordinary conditioned medium. $O$, The activity of either type of conditioned medium is significantly greater $(P<0.05)$ than that of medium devoid of factors from cells. Other details are as described in Fig. 1. 


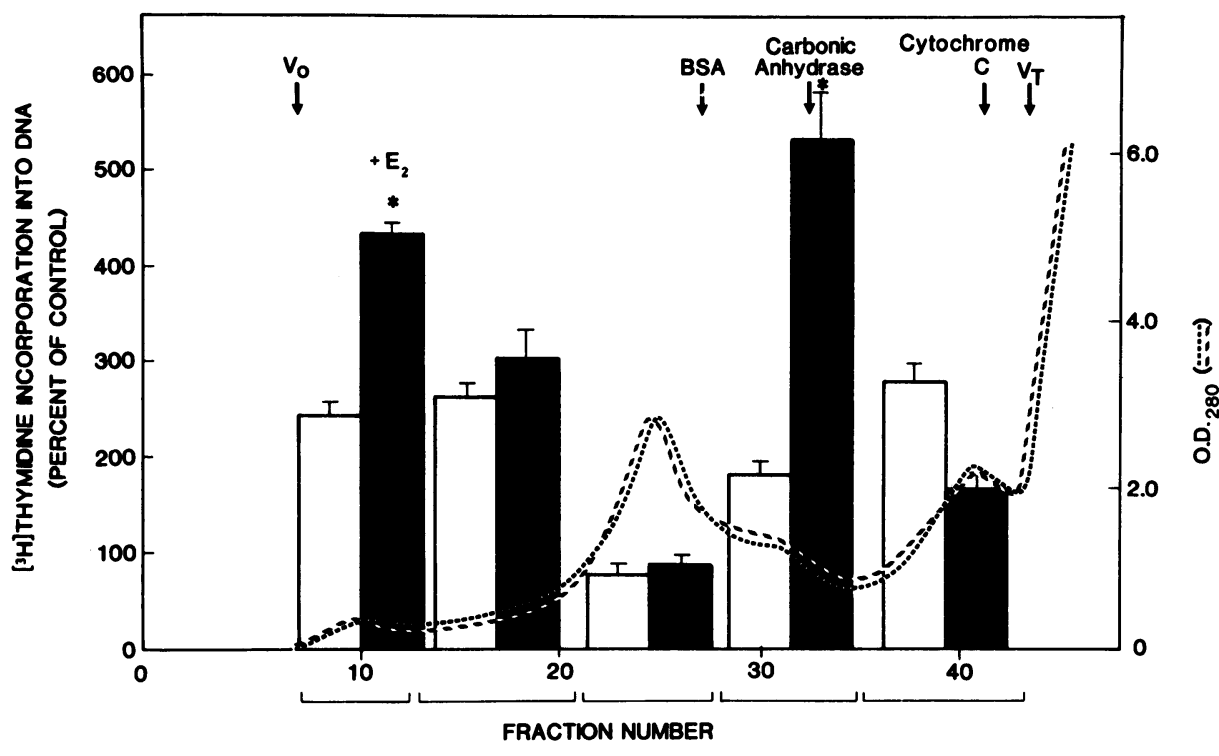

Figure 5. Superose 6B molecular sieve chromatography of estradiol-affected and ordinary conditioned media. Sample volumes of $3 \mathrm{ml}$ were applied to a $1.6 \times 50-\mathrm{cm}$ column, equilibrated, and eluted with $0.05 \mathrm{M}$ ammonium acetate (pH 7.0) containing $0.05 \mathrm{M}$ 2-mercaptoethanol, at a flow rate of $0.05 \mathrm{ml} / \mathrm{min}$ at $4^{\circ} \mathrm{C}$. The protein profile is indicated by absorbance $(O D)$ at $280 \mathrm{~nm}$. The profile of estradiol-affected conditioned medium is shown by the dotted line and that of ordinary "conditioned" medium by the dashed line. $V_{0}$ and $V_{T}$ denote void volume and total column elution volume, respectively. The elution positions of the protein standards, BSA, bovine erythrocyte carbonic anhydrase, and horse heart cytochrome $c$, are also indicated by arrows. Dextran blue and the protein standards were of course analyzed in separate experi-

ments. 2-ml fractions were collected and pooled as indicated by the square brackets. The level of mitogenic activity for $5 \mu \mathrm{g}$ protein of each concentrated pool was calculated as indicated in Fig. 1. Open bars represent the mitogenic activity of pools from ordinary conditioned medium; solid bars represent the activity of pools from estradiol-affected conditioned medium. Both types of conditioned media were from preadipocytes of subject 5 . Error bars represent the SEM calculated from the average of three determinations for each experimental condition. ${ }^{*} P<$ 0.05. Other details are as described for Fig. 1 .

Inhibition of replication was brought about by pool 5 of conditioned medium derived from preadipocytes grown with $\beta \mathrm{E}_{2} ;$ the meaning of this observation was not pursued.

\section{Discussion}

Major implications at both physiologic and pathobiologic levels can be inferred from the finding that preadipocytes cultured with added $\beta \mathrm{E}_{2}$ produce conditioned medium with higher mitogenic activity in the case of cell strains from several massively obese women. This mitogenic effect is probably related to the partially characterized proteins released into the culture medium by massively obese subjects, and proposed as paracrine/autocrine principles, as reported previously (2). These factors probably account, at least partly, for the significantly greater extent of replication of omental preadipocytes from massively obese subjects (9).

These investigations were aimed in part at eluciding the mechanism mediating the promotion of replication by $\beta \mathrm{E}_{2}$ of human preadipocytes, as originally reported by Roncari and Van (1). The original studies were conducted with omental preadipocytes from five lean men and five lean women (1). While the mean level of response did not differ appreciably between the cells from the lean subjects and between these and the preadipocytes from the massively obese women in the present study, more cell strains require analysis before a differential response can be definitively excluded. One should also consider that the response of preadipocytes from massively obese persons to $\beta \mathrm{E}_{2}$ occurs at a significantly higher basal level (without added estrogen) of replication than is the case of cells from lean subjects, as inferred from our previous studies indicating significantly higher degrees of proliferation (9). The current findings, including the fact that the compounds released into the medium result in a mitogenic effect at an earlier time than $\beta \mathrm{E}_{2}$, suggest that the influence of the estrogen is mediated by a paracrine/autocrine factor(s). Ac- cording to the known mechanism of action of estrogens, these hormones probably induce the synthesis of the mitogenic protein(s) by enhancing transcription of the pertinent genes $(12,13)$.

It is notable that $\beta \mathrm{E}_{2}$ had no direct influence on rat perirenal preadipocytes, at least under the conditions that were used. While estrogen receptors were not studied, it is conceivable that receptors for $\beta \mathrm{E}_{2}$ are not expressed in these particular rodent cells, or that they are selectively not functional in terms of mitogenic influence. Obviously, receptors for the mitogenic proteins are present on the rat preadipocytes, the basis in fact for the replication assay in these studies. During evolution, paracrine/autocrine principles long preceded hormones (14-16). It would thus be expected that receptors for the local factors would be ubiquitous throughout evolution and more widespread among cell types, while those for hormones would be more recent and more selective for certain cell types. Rodent tissues such as endometrial and mammary, of course, have estrogen receptors, but as recently reported, rat femoral fat depots, but not perirenal (consistent with the lack of $\beta \mathrm{E}_{2}$ effect on these cells in our studies), parametrial, or subcutaneous dorsal regions, contain a persistent pool of preadipocytes that are dependent on ovarian factors (17). One of these factors is probably estrogen, implying the presence of receptors on femoral preadipocytes. While regional specialization is obvious in pubertal humans, estrogens can act on human adipose cells from various fat tissue regions, suggesting wider distribution of specific receptors.

Dependence on estrogens for production of autocrine/paracrine factors has been studied in greatest detail in the human mammary carcinoma line MCF-7 $(3,4,18-24)$. Mitogenic principles released into the medium include peptides related, at least immunologically, to transforming growth factor-alpha (and thus to epidermal growth factor), to insulin-like growth factor I, as well as a 52,000-D protein. These factors can partially replace estrogens in the promotion of MCF-7 cell growth 
in vitro and in vivo (21). Such observations, as well as our studies of cultured preadipocytes, support the notion that, at least in these two cases, the trophic effects of estrogens are mediated by proteins produced locally.

Even after allowing for the variability of different determinations, considerable variation occurred between cells from different subjects, both in terms of basal release of the mitogenic proteins and degree of stimulation by $\beta \mathrm{E}_{2}$. Since the cells were removed for several generations from the in vivo situation, these disparities probably reflected genetic differences. In turn, such dissimilarities might contribute to individual variation in both distribution of adipose tissue and susceptibility to obesity.

Conceptual extrapolation to events in adipose tissue envisions an amplifying paracrine/autocrine system. In massively obese women and men most of the estrogens are produced in adipose cells by aromatization of adrenal and gonadal androgens, principally estrone from 3,17-androstenedione (5). The newly formed estrogens would act on their own cell of origin and on neighboring cells by autocrine/paracrine mechanisms. The resulting proteins would bring about an increased number of preadipocytes, also by autocrine/paracrine mechanisms. Considering that each locally active system is probably under complex regulation, including partial dependence of the trophic proteins on estrogen, an amplifying paracrine/autocrine chain may be proposed.

As reported, cultured omental preadipocytes from massively obese subjects release much greater quantities of mitogenic proteins than cells from lean subjects (2). We suggest that the higher prevalence of obesity in women may be partially due to higher circulating levels of estrogens, which would promote the production of some of the mitogenic proteins. By interacting with environmental and intrinsic factors, the paracrine/autocrine mechanisms would contribute to the development of obesity in genetically susceptible women. Indeed, a reflection in vitro of the genetic basis of massive corpulence might be the excessive production of the mitogenic proteins by cultured preadipocytes. A particularly vulnerable stage might be pregnancy, which is associated with high levels of circulating estrogens.

As conceptualized, progressive adiposity would be interlinked with increasing autonomy, since the adipose cells would eventually produce most of the estrogens; as suggested by our findings, these hormones would in turn promote the generation of trophic paracrine/autocrine proteins, conferring increasing independence from growth promoting influences external to the expanding adipose tissue of subjects susceptible to massive obesity.

\section{Acknowledgments}

This work was supported by grant MT-8460 from the Medical Research Council of Canada and a grant from the Canadian (Alberta) Heart Foundation. Mr. Cooper was the recipient of a Studentship of the Alberta Heritage Foundation for Medical Research.

\section{References}

1. Roncari, D. A. K., and R. L. R. Van. 1978. Promotion of human adipocyte precursor replication by 17-beta-estradiol in culture. J. Clin. Invest. 62:503-508.

2. Lau, D. C. W., D. A. K. Roncari, and C. H. Hollenberg. 1987. Release of mitogenic factors by cultured preadipocytes from massively obese human subjects. J. Clin. Invest. 79:632-636.

3. Aitken, S. C., M. E. Lippman, A. Kasid, and D. R. Schoenberg. 1985. Relationship between the expression of estrogen-regulated genes and estrogen-stimulated proliferation of $\mathrm{MCF}-7$ mammary tumor cells. Cancer Res. 45:2608-2615.

4. Dickson, R. B., and M. E. Lippman. 1987. Estrogenic regulation of growth and polypeptide growth factor secretion in human breast carcinoma. Endocrine Rev. 8:29-40.

5. Roncari, D. A. K. 1986. Obesity and Lipid Metabolism. In Clinical Medicine. J. A. Spittell, Jr., and R. Volpe, editors. 2nd ed. Harper and Row, Publishers, Inc., Philadelphia. 1-57.

6. Van, R. L. R., C. E. Bayliss, and D. A. K. Roncari. 1976. Cytological and enzymological characterization of adult human adipocyte precursors in culture. J. Clin. Invest. 58:699-704.

7. Van, R. L. R., and D. A. K. Roncari. 1977. Isolation of fat cell precursors from adult rat adipose tissue. Cell Tissue Res. 181:197-203.

8. Van, R. L. R., and D. A. K. Roncari. 1978. Complete differentiation of adipocyte precursors: a culture system for studying the cellular nature of adipose tissue. Cell Tissue Res. 195:317-329.

9. Roncari, D. A. K., D. C. W. Lau, and S. Kindler. 1981. Exaggerated replication in culture of adipocyte precursors from massively obese persons. Metab. Clin. Exp. 30:425-427.

10. Djian, P., D. A. K. Roncari, and C. H. Hollenberg. 1983. Influence of anatomic site and age on the replication and differentiation of rat adipocyte precursors in culture. J. Clin. Invest. 72:12001208.

11. Djian, P., D. A. K. Roncari, and C. H. Hollenberg. 1985. Adipocyte precursor clones vary in capacity for differentiation. Metab. Clin. Exp. 34:880-884.

12. Funder, J. W. 1987. Adrenal steroids: new questions, new answers. Science (Wash. DC). 237:236-237.

13. Evans, R. M. 1988. The steroid and thyroid hormone receptor superfamily. Science (Wash. DC). 240:889-895.

14. Roth, J., D. LeRoith, J. Shiloach, J. L. Rosenzweig, M. A. Lesniak, and J. Havrankova. 1982. The evolutionary origins of hormones, neurotransmitters, and other extracellular chemical messengers. N. Engl. J. Med. 306:523-526.

15. Roth, J., D. LeRoith, J. Shiloach, and C. Rubinovitz. 1983. Intercellular communication: an attempt at a unifying hypothesis. Clin. Res. 31:354-363.

16. LeRoith, D., J. Shiloach, M. Berelowitz, L. A. Frohman, A. S. Liotta, D. T. Krieger, and J. Roth. 1983. Are messenger molecules in microbes the ancestors of the vertebrate hormones and tissue factors? Fed. Proc. 42:2602-2607.

17. Krakower, G. R., R. G. James, C. Arnaud, J. Etienne, R. H. Keller, and A. H. Kissebah. 1988. Regional adipocyte precursors in the female rat. Influence of ovarian factors. J. Clin. Invest. 81:641-648.

18. Westley, B., and H. Rochefort. 1980. A secreted glycoprotein induced by estrogen in human breast cancer cell lines. Cell. 20:353362.

19. Lippman, M. E., and A. Kasid. 1983. Role of receptors in mediating steroid hormone effects in human breast cancer. Cancer Treat. Rep. 68:265-279.

20. Lippman, M. E., R. B. Dickson, A. Kasid, E. Gelmann, N. Davidson, M. McManaway, K. Huff, D. Bronzert, S. Bates, S. Swain, and C. Knabbe. 1986. Autocrine and paracrine growth regulation of human breast cancer. J. Steroid Biochem. 24:147-154.

21. Dickson, R. B., M. E. McManaway, and M. E. Lippman. 1986. Estrogen-induced factors of breast cancer cells partially replace estrogen to promote tumor growth. Science (Wash. DC). 232:1540-1543.

22. Dickson, R. B., K. K. Huff, E. M. Spencer, and M. E. Lippman. 1986. Induction of epidermal growth factor-related polypeptides by 17-beta-estradiol in MCF-7 human breast cancer cells. Endocrinology. 118:138-142.

23. Vignon, F., F. Capony, M. Chambon, G. Freiss, M. Garcia, and H. Rochefort. 1986. Autocrine growth stimulation of the MCF-7 breast cancer cells by the estrogen-regulated $52 \mathrm{~K}$ protein. Endocrinology. 118:1537-1545.

24. Dickson, R. B., A. Kasid, K. K. Huff, S. E. Bates, C. Knabbe, D. Bronzert, E. P. Gelmann, and M. E. Lippman. 1987. Activation of growth factor secretion in tumorigenic states of breast cancer induced by 17-beta-estradiol or v-Ha-ras oncogene. Proc. Natl. Acad. Sci. USA. 85:837-841. 